\title{
Minichromosome maintenance protein 7 as prognostic marker of tumor aggressiveness in pituitary adenoma patients
}

\author{
Antonella Coli, Sylvia L Asa', Guido Fadda, Domenico Scannone, Sabrina Chiloiro², \\ Laura De Marinis ${ }^{2}$, Liverana Lauretti ${ }^{3}$, Franco 0 Ranelletti ${ }^{4}$ and Libero Lauriola \\ Department of Anatomic Pathology, Catholic University, Largo F Vito 1, 00168 Rome, Italy, 'Department of \\ Laboratory Medicine and Pathobiology, University of Toronto, Ontario, Canada, Departments of ${ }^{2}$ Endocrinology, \\ ${ }^{3}$ Neurosurgery and ${ }^{4}$ Histology, Catholic University, Rome, Italy
}

Correspondence should be addressed to A Coli Email

antonella.coli@rm.unicatt.it

\begin{abstract}
Background: Ki-67 labeling index (LI) is currently regarded as a useful prognostic marker of pituitary adenoma (PA) clinical behavior, although its relevance as a reliable clinical indicator is far from being universally accepted, since both validations and criticisms are found in the literature. Minichromosome maintenance 7 (MCM7), a cell-cycle regulator protein, has been recently proposed as a marker of tumor aggressiveness in tumors from many sites, including the CNS. Therefore, we evaluated MCM7, in comparison to Ki-67, as a potential marker of clinical outcome in PA.

Design and methods: In this single-institution retrospective study, 97 patients with PA (23 ACTH, 12 GH, 29 PRL, 10 FSH/LH, and 23 non-secreting adenomas) were recruited and the prognostic value of both MCM7 and Ki-67 was evaluated by immunohistochemical techniques. In addition, p53 nuclear expression and mitotic index were also evaluated.

Results: Twenty-six of the 97 PA patients recurred during the follow-up period. Cox's regression analysis showed that high nuclear expression of MCM7 LI, unlike Ki-67 LI, was directly associated with a higher (7.7-fold) risk of recurrence/progression. Kaplan-Meier analysis of recurrence/progression-free survival curves revealed that patients with high MCM7 LI ( $\geq 15 \%)$ had a shorter recurrence/progression-free survival than those with low MCM7 LI ( $<15 \%)$. Moreover, among patients with invasive tumors, high MCM7 LI identified those with the highest risk of recurrence/progression.

Conclusions: Data from this study suggest that MCM7 is a prognostic marker of clinical outcome in PA patients, more reliable and informative than Ki-67.
\end{abstract}

\section{Introduction}

Pituitary adenomas (PAs) are neoplasms arising from the anterior pituitary gland, accounting for $\sim 15 \%$ of intracranial tumors. Many of these tumors present with signs of compression or invasion of adjacent structures, such as cavernous sinus, sphenoid bone, or nasopharynx and some recur locally $(1,2)$. PAs are currently classified by imaging, clinical and biochemical findings, histology, and immunohistochemistry.

The WHO 2004 classification, in addition to typical adenomas and pituitary carcinomas, recognizes atypical adenomas by the presence of a Ki-67 labeling index (LI) (c) 2016 European Society of Endocrinology Printed in Great Britain
$>3 \%$, invasive growth, elevated mitotic index (MI), and nuclear staining for p53 (3). However, several studies did not confirm the correlation of these criteria with clinical behavior and aggressiveness of each individual adenoma $(4,5,6,7,8,9,10)$. In particular, the Ki-67 LI, widely used to determine cellular growth fraction in many types of tumors, is accepted as prognostic indicator in pituitary tumors, although controversial results have emerged from clinical studies and criticisms are also reported in the literature $(6,11,12,13,14,15)$. Other markers have been proposed to assess the aggressiveness of $\mathrm{PA}$, among which

Published by Bioscientifica Ltd. 
pituitary tumor transforming gene, p27, p16, galectin-3, and cyclin D1, but none of them has gained general acceptance as prognostic indicator $(9,16,17,18,19,20)$. Therefore, useful predictors of PA behavior remain to be found for appropriate surveillance and treatment.

Minichromosome maintenance (MCM) family proteins, evolutionary conserved in all eukaryotes, consist of six main DNA-binding members, from MCM2 to MCM7, interacting with each other to form a heterohexamer complex that localizes in the nucleus $(21,22)$. They are tightly bound to chromatin in the late mitotic phase and G1, and removed in the S and G2 phases (23). MCM proteins have been demonstrated only in replicating cells, and are considered to function as licensing components for S-phase of the cell cycle. These proteins display weak helicase activity, and are involved in several aspects of transcriptional control (24). MCM protein activity is modulated by various molecules, including cyclins, growth factors, retinoblastoma tumor suppressor protein, p21, p27, and pTEN and they are regulated by a range of molecular pathways, such as phosphorylation, ubiquitylation, and acetylation $(19,22,24,25,26,27)$.

Recently, MCM family proteins, although barely detectable in normal tissues, restricted to actively proliferating cells, have been found to be significantly up-regulated in several human tumors, including melanomas, endometrial, gastro-intestinal, and prostate cancers as well as gliomas $(28,29,30,31,32,33,34,35$, $36,37,38)$. In particular, MCM7 overexpression and amplification has been found to predict a poor clinical outcome in tumor patients $(39,40,41,42,43,44,45)$. Since MCM7 in human pituitary tumors has not still studied, we investigated the expression of MCM7, in comparison to Ki-67 as prognostic markers of clinical behavior in PA patients.

\section{Subjects and methods}

\section{Patients}

PA from 97 patients (59 females and 38 males) undergoing trans-sphenoidal surgery were retrospectively studied, on approval by the Bioethic Committee of the Università Cattolica del S. Cuore (Protocol.cm number: 11192/14). The median age of patients at the time of first surgery was 41 years, ranging from 9 to 90 years (mean \pm s.e.M. $=42.2 \pm$ 1.7). This study included only patients undergoing surgical resection for PA without a history of previous medical treatment. In fact, for the peculiarity of this morphological study, we excluded patients receiving medical treatment prior to neurosurgery, since it is possible that therapies can suppress or decrease the expression of proliferative molecular markers, as suggested by Sánchez-Tejada et al. (46).

PAs were classified by size, determined by magnetic resonance imaging (MRI) before surgery, as microadenomas $(\leq 10 \mathrm{~mm})$ and macroadenomas $(>10 \mathrm{~mm})$. PA invasiveness was assessed by preoperative MRI integrated with intraoperative evaluation; suprasellar extension was not considered invasion. On the basis of these data 57/97 (58\%) tumors were not invasive and 40/97 (42\%) were invasive.

The tumors were classified by immunohistochemistry on the basis of hormonal production in the following subgroups: adrenocorticotrophic hormone (ACTH) adenomas $(n=23)$, growth hormone $(\mathrm{GH})$ adenomas $(n=12)$, prolactin (PRL) adenomas $(n=29)$, follicle-stimulating hormone/luteinizing hormone (FSH/LH) adenomas $(n=10)$ and non-immunoreactive adenomas $(n=23)$. Gonadotroph adenoma was diagnosed by the presence of a partially and patchy immunopositivity for $\beta$-FSH and $\beta$-LH with pseudorosette or papillary pattern, according to the literature (3). Due to the limited number of cases in each hormonal group, no further subgrouping was attempted. After surgery, patients undergone a follow-up program, though MRI and biochemical tests, receiving appropriate therapy in case of recurrence/progression. Radical excision was defined as no evidence of tumor remnant at postoperative MRI; in functioning adenomas, also hormonal remission had to be proven. Recurrence was defined, in functioning-PAs, as hormonal and/or radiological disease reactivation, during follow-up, in patients who had undergone tumor radical excision. In nonfunctioning PAs, recurrence was defined as radiological evidence of disease reactivation during follow-up in patients who had undergone tumor radical excision. Progression was defined as regrowth in tumor size based on MRI and/or evidence of an increase in plasma hormone levels in partially resected secreting PAs.

\section{Immunohistochemistry}

Tumor tissue was fixed in $4 \%$ buffered formalin and embedded in paraffin, according to standard procedures. Five-micrometer-thick sections were deparaffinized in xylene, rehydrated, treated with $0.3 \% \mathrm{H}_{2} \mathrm{O}_{2}$ in methanol for 10 min to block endogenous peroxidase activity, and subjected to heat-induced epitope retrieval in sodium citrate buffer $(\mathrm{pH}=6.0)$ in microwave oven. Immunohistochemistry was performed with either a Ventana 
Benchmark XT Autostainer (Ventana Medical System, AZ, USA) or Dako AutostainerLink 48 (Dako, CA, USA) according to the manufacturer's instructions. The following primary antibodies were used: anti-Synaptophysin (clone SP11; Ventana Medical System; prediluted), anti-Cytokeratin (CAM 5.2; UCS Diagnostic, Rome, Italy; 1:100), anti-ACTH (clone 02A3; Dako; 1:100), anti-GH (polyclonal; Dako; 1:200), anti-PRL (polyclonal; Dako; 1:400), anti-FSH (clone C10; Dako; 1:500), anti-LH (clone C93; Dako; 1:50), anti-MCM7 (clone 141.2; Santa Cruz Biotechnology, TX, USA; 1:100), anti-Ki-67 (clone 30-9; Ventana Medical System; prediluted); and anti-p53 (clone Bp53-11; Ventana Medical System; prediluted). Normal peritumoral pituitary tissue, frequently present, was used as positive control for pituitary hormone antibodies; MCM7, Ki-67, and p53 proteins were practically undetectable in normal pituitary tissue. Negative controls were performed by omitting the primary antibodies.

\section{Evaluation of Ki-67, MCM7, p53, and MI}

Slides were observed with a Zeiss Axioskop 2 microscope and labeling counts for MCM7, Ki67, and p53 antibodies were performed on a monitor, with a JVC color videocamera. Five randomly-selected fields, each containing at least 400 cells were counted independently by two pathologists and LI for each antibody was calculated as a percentage of immunostained nuclei.

MI, reported as number of mitoses in 10 high power fields (HPF), was obtained by dividing by five the number of mitosis counted in $50 \mathrm{HPF}$.

\section{Statistical analysis}

Recurrence/progression-free survival was calculated from the first surgery to the date of recurrence/progression occurrence. All medians and life tables were computed using the product-limit estimate by Kaplan and Meier, and the curves were examined by the log-rank test. Relative risks (RRs) of recurrence were calculated by the Cox's proportional hazards model. All $P$ values were doublesided. Statistical analyses were done by JMP 11 software (SAS Institute, Inc., Cary, NC, USA).

\section{Results}

All adenoma samples showed variable nuclear MCM7 and Ki-67 immunolabeling (Fig. 1). No substantial labeling for either proteins was found in the fragments of normal pituitary tissue frequently present in biopsy material.

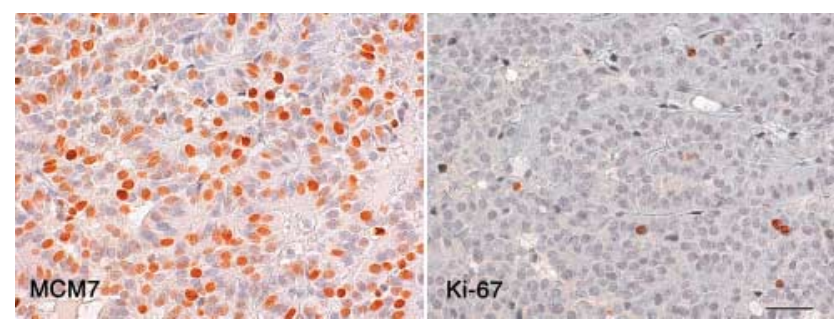

\section{Figure 1}

Immunohistochemical analysis of MCM7 (left panel) and Ki-67 (right panel) expression in PA. Shown is the nuclear immunolocalization of both antigens in the same PA. MCM7 and $\mathrm{Ki}-67$ labeling indices were $30 \%$ and $3 \%$ respectively. Bar scale $=50 \mu \mathrm{m}$.

The overall mean \pm s.e.M. of MCM7 and Ki-67 LI were $15.0 \% \pm 1.5$ (median: $10 \%$; range, $1-70$ ) and $3.0 \% \pm 0.2$ (median: 3\%; range, 1-10) respectively. The overall mean \pm s.e.M. of p53 and MI were 2.93 (median: 2.0; range, 0-25) and 0.46 (median: 0; range, 0-8) respectively. Interestingly, MCM7, Ki-67 LI, p53 LI, and MI did not show a significant correlation among them. Ki-67 was significantly associated with the patients' youngest age ( $<40$ years), while MCM7 was associated with gender (highest in females) and hormonal type (highest in ACTH and GH adenomas). p53 LI was associated only with gender (highest in females), while MI did not show any association with the clinico-pathological characteristics considered (Table 1).

Among adenoma subtypes, only invasive ACTH adenomas showed higher MCM7 LI $(P=0.0023)$ (Table 2). Accordingly, all ACTH adenomas with MCM7 LI <15\% (9/9; 100\%) were not invasive, while $43 \%(6 / 14)$ of $\mathrm{MCM} 7 \mathrm{LI} \geq 15 \%$ adenomas were invasive (Fisher's exact test $P=0.048$ ). Relative to Ki-67, no significant differences were found between invasive and non invasive adenoma subtypes.

During the follow-up period (median: 18 months; range: 1-120), 26 out of 97 (26.8\%) patients had recurrence/progression. The mean time to recurrence/ progression was $23.8 \pm 5.12$ s.e.m. months (median: 19 ; range: 1-96). Cox's regression analysis, using MCM7 and Ki-67 LI as continuous covariates, showed that high MCM7 LI values, but neither p53 LI nor Ki-67 and MI, were directly associated with the risk of recurrence/progression. The risk ratio of recurrence/progression, per unit change of MCM7 LI was 1.04 (95\% CI=1.02-1.06; $P<0.0001)$. Patients with high MCM7 LI ( $\geq 15 \%)$ showed a 7.7-fold higher $\mathrm{RR}$ of recurrence/progression (95\% $\mathrm{CI}=3.1-23.2)$ 
Table 1 MCM7, Ki-67, p53, and mitotic index according to clinicopathological characteristics of the PA patients.

\begin{tabular}{|c|c|}
\hline Variables & $n$ \\
\hline \multicolumn{2}{|l|}{ Age } \\
\hline$\leq 40$ & 48 \\
\hline$>40$ & 49 \\
\hline \multicolumn{2}{|l|}{ Sex } \\
\hline Female & 59 \\
\hline Male & 38 \\
\hline \multicolumn{2}{|l|}{ Dimension } \\
\hline Microadenoma & 23 \\
\hline Macroadenoma & 74 \\
\hline \multicolumn{2}{|l|}{ Hormonal type } \\
\hline LH-FSH & 10 \\
\hline ACTH & 23 \\
\hline $\mathrm{GH}$ & 12 \\
\hline PRL & 29 \\
\hline Non-secreting & 23 \\
\hline
\end{tabular}

\begin{tabular}{|c|c|c|}
\hline MCM7 LI & $\boldsymbol{P}^{\mathrm{b}}$ & Ki-67 LI \\
\hline $\begin{array}{r}16.54^{c} \pm 2.08 \\
13.51 \pm 2.06\end{array}$ & 0.1 & $\begin{array}{l}3.48 \pm 0.26 \\
2.47 \pm 0.26\end{array}$ \\
\hline $\begin{array}{l}15.57 \pm 1.89 \\
14.13 \pm 2.35\end{array}$ & 0.04 & $\begin{array}{l}2.86 \pm 0.25 \\
3.13 \pm 0.31\end{array}$ \\
\hline $\begin{array}{l}16.04 \pm 3.03 \\
14.69 \pm 1.69\end{array}$ & 0.7 & $\begin{array}{l}2.74 \pm 0.39 \\
3.04 \pm 0.22\end{array}$ \\
\hline $\begin{array}{l}10.70 \pm 4.40 \\
22.61 \pm 2.90 \\
18.01 \pm 4.02 \\
12.69 \pm 2.58 \\
10.65 \pm 2.90\end{array}$ & 0.04 & $\begin{array}{l}2.30 \pm 0.60 \\
2.87 \pm 0.39 \\
3.08 \pm 0.55 \\
3.41 \pm 0.35 \\
2.74 \pm 0.39\end{array}$ \\
\hline
\end{tabular}

\begin{tabular}{c}
$\boldsymbol{P}$ \\
\hline 0.008 \\
0.5 \\
0.1 \\
\hline
\end{tabular}

\begin{tabular}{c}
\hline $\mathbf{p 5 3}(\%)$ \\
\hline \\
$3.17 \pm 0.69$ \\
$2.68 \pm 0.68$ \\
$3.79 \pm 0.61$ \\
$1.63 \pm 0.75$ \\
$2.42 \pm 0.96$ \\
$3.14 \pm 0.56$ \\
$4.80 \pm 1.45$ \\
$2.52 \pm 0.95$ \\
$6.10 \pm 1.38$ \\
$2.11 \pm 0.86$ \\
$2.01 \pm 0.96$ \\
\hline
\end{tabular}

\begin{tabular}{c}
\hline $\boldsymbol{P}$ \\
\hline 0.9 \\
0.01 \\
0.7 \\
0.3 \\
\hline
\end{tabular}

\begin{tabular}{|c|c|}
\hline $\begin{array}{c}\text { Mitotic index } \\
\quad(\times 10 \mathrm{HPF})\end{array}$ & $\boldsymbol{P}$ \\
\hline $\begin{array}{l}0.55 \pm 0.26 \\
0.38 \pm 0.16\end{array}$ & 0.3 \\
\hline $\begin{array}{l}0.46 \pm 0.15 \\
0.47 \pm 0.19\end{array}$ & 0.5 \\
\hline $\begin{array}{l}0.47 \pm 0.14 \\
0.47 \pm 0.24\end{array}$ & 1.0 \\
\hline $\begin{array}{l}0.90 \pm 0.34 \\
0.44 \pm 0.24 \\
0.35 \pm 0.34 \\
0.45 \pm 0.22 \\
0.37 \pm 0.24\end{array}$ & 0.9 \\
\hline
\end{tabular}

ababeling index.

${ }^{b}$ Wilcoxon/Kruskal-Wallis test.

'Mean \pm s.E.M.

as compared to patients with low MCM7 LI $(<15 \%)$. The plot of the estimate, at a 5-year follow-up, of recurrence/progression-free survival as a function of MCM7 LI, shows that the increase of MCM7 LI is associated with the reduction of the percentage of recurrence/progression-free patients (Fig. 2).

For recurrence/progression-free survival analysis, MCM7 and Ki-67 LI values were converted to binomial variables of high vs low expression based on receiver operating characteristics (ROC) analysis. According to the ROC analysis, cut-off values of $\geq 15 \%$ and $\geq 3 \%$ for MCM7 and $\mathrm{Ki}-67$ respectively, were chosen in order to facilitate the interpretation and to maximize the efficiency of comparisons. Recurrence/progression-free survival curves for patients with high or low MCM7 and Ki-67 LI tumor status is shown in Fig. 3. Kaplan-Meier analysis of recurrence/progression-free survival curves revealed that patients with high MCM7 LI ( $\geq 15 \%)$ had a shorter recurrence/progression-free survival than patients with low MCM7 LI $(<15 \%)$ (log-rank test, $P<0.0001)$. At 5 years' follow-up the mean \pm s.E.M. of recurrence/progression-free survival was $36 \% \pm 9.6$ and $87 \% \pm 7.9$ for patients with high and low MCM7 respectively. On the contrary, Ki-67 LI values (Fig. 3), as well as p53 and MI (data not shown), could not identify patients at high risk of recurrence/progression.

Univariate analysis of prognostic covariates revealed that high MCM7 LI and invasiveness were associated with an increased risk of recurrence/progression and, as revealed by the multivariate analysis, both MCM7 LI and invasiveness retained an independent negative prognostic significance relative to the risk of recurrence/progression (Table 3). Cox's proportional hazard model analysis of RR of recurrence/progression as a function of tumor status relative to both MCM7 LI and invasiveness showed that invasive tumors with high MCM7 LI had a 16-fold higher

Table 2 MCM7 and Ki-67 LIs in non-invasive and invasive PA.

\begin{tabular}{|c|c|c|c|c|c|c|}
\hline & \multicolumn{3}{|c|}{ MCM7 LI } & \multicolumn{3}{|c|}{ Ki-67 LI } \\
\hline & Non-invasive & Invasive & $P^{a}$ & Non-invasive & Invasive & $P$ \\
\hline ACTH & $14.8 \pm 2.8(17)^{b}$ & $44.8 \pm 4.8(6)$ & 0.0023 & $3.0 \pm 0.4(17)$ & $2.5 \pm 0.7(6)$ & 0.62 \\
\hline $\mathrm{GH}$ & $11.2 \pm 6.1(8)$ & $31.7 \pm 8.7(4)$ & 0.23 & $2.5 \pm 0.7(8)$ & $4.2 \pm 1.0(4)$ & 0.29 \\
\hline $\mathrm{NSA}^{\mathrm{c}}$ & $8.6 \pm 3.6(9)$ & $12.0 \pm 2.9(14)$ & 0.34 & $2.9 \pm 0.4(9)$ & $2.6 \pm 0.3(14)$ & 0.58 \\
\hline PRL & $13.4 \pm 2.3(20)$ & $11.0 \pm 3.5(9)$ & 0.30 & $3.1 \pm 0.4(20)$ & $4.1 \pm 0.6(9)$ & 0.81 \\
\hline FSH/LH & $8.3 \pm 7.1(3)$ & $11.7 \pm 4.6(7)$ & 0.90 & $1.7 \pm 1.7(3)$ & $2.6 \pm 1.1(7)$ & 1.00 \\
\hline
\end{tabular}


Table 3 Univariate and multivariate analyses of prognostic covariates in PA patients.

\begin{tabular}{|c|c|c|c|c|c|c|}
\hline & \multicolumn{3}{|c|}{ Univariate analysis } & \multicolumn{3}{|c|}{ Multivariate analysis } \\
\hline & $\mathrm{RR}^{\mathrm{a}}$ & $95 \% \mathrm{Cl}^{\mathrm{b}}$ & $P^{c}$ & $\mathrm{RR}^{\mathrm{d}}$ & $95 \% \mathrm{Cl}$ & $P$ \\
\hline \multicolumn{7}{|l|}{ Age } \\
\hline$\leq 40$ & $1^{e}$ & & & 1 & & \\
\hline$>40$ & 1.22 & $0.55-2.68$ & 0.61 & 1.37 & $0.50-3.78$ & 0.53 \\
\hline \multicolumn{7}{|l|}{ Sex } \\
\hline Female & 1 & & & 1 & & \\
\hline Male & 1.21 & $0.55-2.76$ & 0.64 & 0.64 & $0.26-1.52$ & 0.31 \\
\hline \multicolumn{7}{|l|}{ Histological type } \\
\hline LH-FSH & 1 & & & 1 & & \\
\hline ACTH & 2.48 & $0.45-46.16$ & 0.34 & 1.69 & $0.28-32.65$ & 0.61 \\
\hline $\mathrm{GH}$ & 2.87 & $0.37-58.07$ & 0.33 & 2.98 & $0.34-63.22$ & 0.33 \\
\hline PRL & 1.38 & $0.25-25.89$ & 0.75 & 1.37 & $0.18-28.48$ & 0.78 \\
\hline Non-secreting & 1.39 & $0.20-27.21$ & 0.76 & 1.20 & $0.16-24.58$ & 0.87 \\
\hline \multicolumn{7}{|l|}{ Invasiveness } \\
\hline No & 1 & & & 1 & & \\
\hline Yes & 3.60 & $1.64-8.30$ & 0.0015 & 3.04 & $1.11-8.87$ & 0.029 \\
\hline \multicolumn{7}{|l|}{ Ki-67 } \\
\hline$\leq 3 \%$ & 1 & & & 1 & & \\
\hline$>3 \%$ & 0.99 & $0.42-2.19$ & 0.98 & 1.34 & $0.47-3.66$ & 0.57 \\
\hline \multicolumn{7}{|l|}{ MCM7 } \\
\hline$<15 \%$ & 1 & 1 & & & & \\
\hline$\geq 15 \%$ & 7.70 & $3.12-23.17$ & $<0.0001$ & 5.94 & $2.14-19.30$ & 0.0005 \\
\hline
\end{tabular}

risk of recurrence/progression relative to non-invasive tumors expressing low MCM7 LI. Moreover, among patients with invasive tumors, high MCM7 LI identified those with the highest risk of recurrence/ progression (Table 4).

\section{Discussion}

In the search for markers of PA aggressiveness, many biological molecules have been investigated, including growth factors and their receptors, angiogenic factors, matrix metalloproteinases, miRNAs, and many others, but none of them has gained wide acceptance and use $(9,17,18,19,47)$.

Ki-67 LI $>3 \%$ has been proposed by the $2004 \mathrm{WHO}$ classification as a marker of atypical adenomas, along with the presence of mitoses and p53 nuclear labeling, although its effectiveness is far from being universally accepted $(3,6,9,12,13,15,17,19)$. In a recent study, it has been shown that the 3\% cut-off for Ki-67 has a low sensitivity along with an elevated specificity, but these values change in various types of PAs (15). In the present series neither p53 nor MI behave as prognostic indicator of worse clinical outcome, according to previous observations $(5,8,48)$.

Many studies have shown the value of MCM family proteins as diagnostic and prognostic markers in many

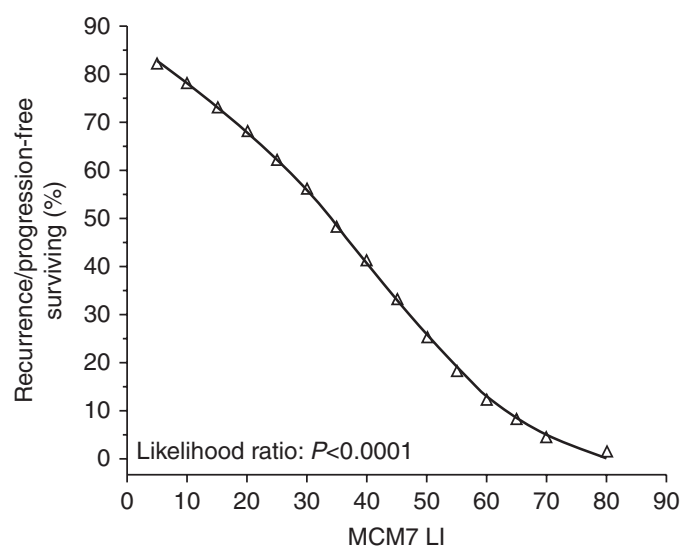

Figure 2

Plot of the estimate of recurrence/progression-free survival as a function of MCM7 LI. The proportional hazard model was evaluated at each covariate value and the proportion of patients without event at 5-year follow-up was estimated from the computed survival function. 
Table 4 Cox's proportional hazard model analysis of relative risk (RR) of recurrence/progression as a function of tumor status relative to $\mathrm{MCM} 7 \mathrm{LI}$ and invasiveness.

\begin{tabular}{|c|c|c|c|}
\hline Group & $\mathbf{R R}$ & $95 \% \mathrm{Cl}^{\mathrm{a}}$ & $\boldsymbol{P}^{\mathrm{b}}$ \\
\hline $\begin{array}{c}\text { MCM7 }<15 \%- \\
\text { non-invasive }\end{array}$ & $1^{c}$ & & \\
\hline $\begin{array}{l}\text { MCM7 } \geq 15 \%- \\
\text { non-invasive }\end{array}$ & 5.57 & $1.54-25.91$ & 0.0067 \\
\hline MCM7 $\geq 15 \%$ - invasive & 15.98 & $5.09-70.55$ & $<0.0001$ \\
\hline MCM7 $<15 \%$ - invasive & 2.02 & $0.26-12.29$ & 0.45 \\
\hline
\end{tabular}

a $95 \%$ confidence interval.

bikelihood ratio test.

'Reference group.

tumor types $(26,27,28,29,30,31,32,33,34,35,36,37$, $38,39,40,41,42,43,44,45)$ and we hereby report that, in PAs, MCM7 may be a possible marker of pituitary tumor aggressiveness.

In our study on 97 PA patients MCM7 LI displayed a higher capability in predicting the risk of recurrence/ progression in comparison with Ki-67 LI. The remarkably different values of nuclear staining between MCM7 and Ki-67 (Table 1) can be explained by data in literature showing that $\mathrm{Ki}-67$ protein is restricted to a fraction of proliferating cells and rapidly disappears when they enter a resting state, while MCM7 protein is stable throughout the cell cycle, identifying a larger pool of cycling cells in a resting state but 'licensed' to enter replication $(22,28)$.

In our patient series, we were unable to find a direct association of Ki-67 LI, p53 LI, and MI with the risk of recurrence/progression. On the contrary, patients with high MCM7 LI ( $\geq 15 \%$ ) had a shorter recurrence/progression-free survival and a 7.7-fold higher RR of recurrence/ progression, in comparison to patients with low MCM7 LI.

In agreement with the recent observations by Righi et al. in a series of 166 patients with pituitary tumors (15), we found that invasion is significantly associated with recurrence/progression (Table 3). In PA, apart from a limited number of ACTH adenomas, MCM7 LI, and invasiveness are not associated, suggesting that MCM7 expression and invasiveness are two independent characteristics of PA (Table 2). This result is consistent with the observed absence of interaction between invasion and proliferation in a large multicentric investigation on PA (49) and with the finding that MCM7 LI and tumor invasiveness behave as independent prognostic markers relative to the recurrence/progression-free survival (Table 3). It has been recently reported a 12-fold higher probability of recurrence/progression in patients with invasive and proliferative PA, as compared to patients with non-invasive and a non-proliferative tumors (49). Consistent with this observation, MCM7 LI and tumor invasiveness, when combined, behave as a strong prognostic marker, identifying the subgroup of patients (MCM7 $\geq 15 \%$ - invasive) with the highest $R R(R R=16$ fold) of recurrence/progression (Table 4).

Due to the limited number of cases in this study, our preliminary observations on the prognostic role of MCM7 in PA must be confirmed in a larger cohort of patients, with a more extended follow-up. In addition to other markers, MCM7 could be useful in the postoperative management of $\mathrm{PA}$, in order to identify patients at a higher recurrence risk and decide for a more compelling follow-up or a more aggressive postsurgical treatment.
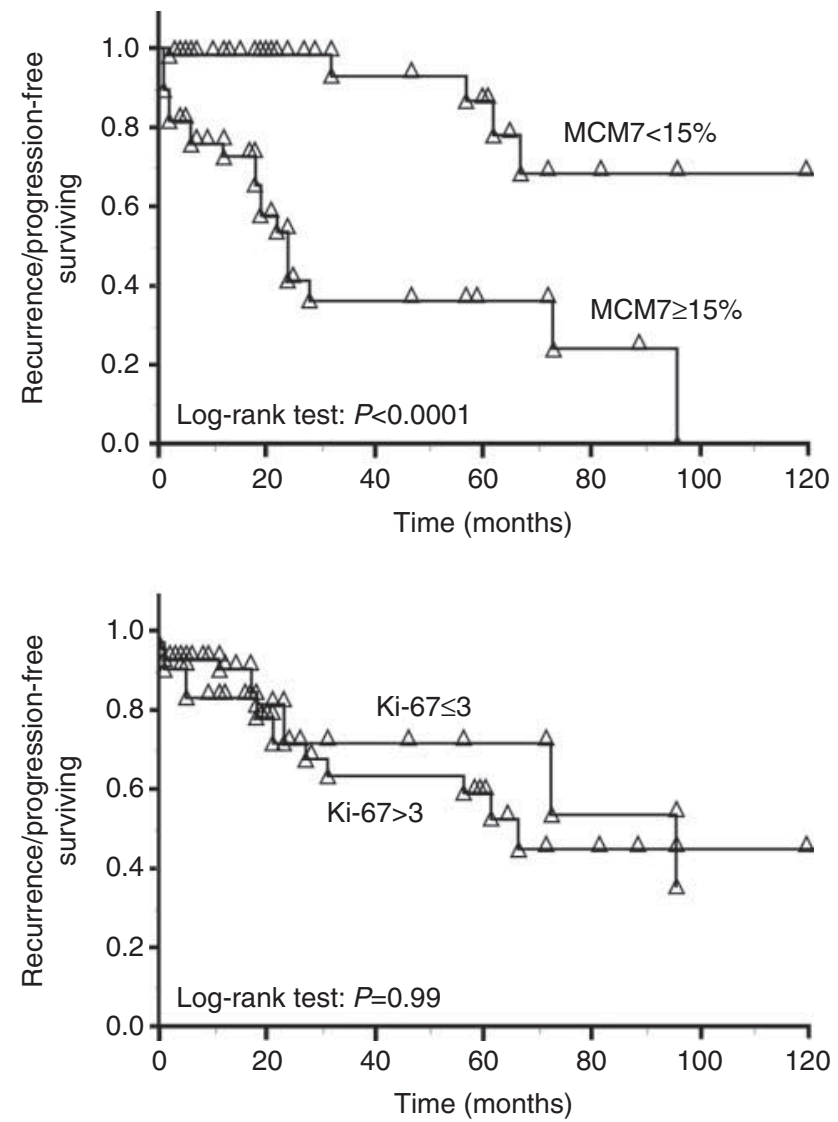

Figure 3

Kaplan-Meier analysis of recurrence/progression-free survival curves as a function of MCM7 and Ki-67 status in PA patients. The reported cut-off values were chosen on the basis of the receiver operating characteristic curve analyses. 


\section{Conclusion}

Our study indicates that an overexpression of MCM7 in PA is significantly associated with early recurrence/ progression and a poor clinical outcome and that it might be regarded as a candidate marker for surveillance in PA patients. Additional studies are needed to elucidate the function and significance of MCM7 expression in PAs and to cross-validate its use as a prognostic marker for surveillance and prognosis.

\section{Declaration of interest}

The authors declare that there is no conflict of interest that could be perceived as prejudicing the impartiality of the research reported.

\section{Funding}

This work was supported by the Catholic University of Sacred Heart, Grants to Profs F O Ranelletti and L Lauriola (D1-70200974 and D1-70201038).

\section{References}

1 Asa SL. Tumors of the pituitary gland. Fascicle 15, 4th Series. In The Atlas of Tumor Pathology. pp 55-172. Washington DC: Armed Forces Institute of Pathology, 2011.

2 Mete O \& Asa SL. Clinicopathological correlations in pituitary adenomas. Brain Pathology 201222 443-453. (doi:10.1111/j.1750-3639. 2012.00599.x)

3 Lloyd RV, Kovacs K, Young WF Jr, Farrell WE, Asa SL, Trouillas J, Kontogeorgos G, Sano T, Scheithauer BW, Horvath E. Pituitary tumours: Introduction. In World Health Pathology and Genetics of Tumours of Endocrine Organs, ch. 1, pp 10-13. Eds RA DeLellis, RV Lloyd, PU Heitz \& C Eng. Lyon: IARC Press, 2004.

4 Losa M, Franzin A, Mangili F, Terreni MR, Barzaghi R, Veglia F, Mortini P \& Giovanelli M. Proliferation index of nonfunctioning pituitary adenomas: correlations with clinical characteristics and long-term follow-up results. Neurosurgery 200047 1313-1318. (doi:10.1097/00006123-200012000-00009)

5 Hentschel SJ, McCutcheon IE, Moore W \& Durity FA. P53 and MIB-1 immunohistochemistry as predictors of the clinical behavior of nonfunctioning pituitary adenomas. Canadian Journal of Neurological Sciences 200330 215-219. (doi:10.1017/S0317167100002614)

6 Scheithauer BW, Gaffey TA, Lloyd RV, Sebo TJ, Kovacs KT, Horvath E, Yapicier O, Young WF Jr, Meyer FB, Kuroki T et al. Pathobiology of pituitary adenomas and carcinomas. Neurosurgery 200659 341-353. (doi:10.1227/01.NEU.0000223437.51435.6E)

7 Dubois S, Guyétant S, Menei P, Rodien P, Illouz F, Vielle B \& Rohmer V. Relevance of Ki-67 and prognostic factors for recurrence/progression of gonadotropic adenomas after first surgery. European Journal of Endocrinology/European Federation of Endocrine Societies $2007 \mathbf{1 5 7}$ 141-147. (doi:10.1530/EJE-07-0099)

8 Gejman R, Swearingen B \& Hedley-Whyte ET. Role of Ki-67 proliferation index and p53 expression in predicting progression of pituitary adenomas. Human Pathology 200839 758-766. (doi:10.1016/j.humpath.2007.10.004)

9 Sav A, Rotondo F, Syro LV, Scheithauer BW \& Kovacs K. Biomarkers of pituitary neoplasms. Anticancer Research 201232 4639-4654.
10 Chiloiro S, Doglietto F, Trapasso B, Iacovazzo D, Giampietro A, Di Nardo F, de Waure C, Lauriola L, Mangiola A, Anile C et al. Typical and atypical pituitary adenomas: a single-center analysis of outcome and prognosis. Neuroendocrinology 2015101 143-150. (doi:10.1159/000375448)

11 Thapar K, Kovacs K, Scheithauer BW, Stefaneanu L, Horvath E, Pernicone PJ, Murray D \& Laws ER Jr. Proliferative activity and invasiveness among pituitary adenomas and carcinomas: an analysis using the MIB-1 antibody. Neurosurgery 199638 99-107. (doi:10.1097/ 00006123-199601000-00024)

12 Salehi F, Agur A, Scheithauer BW, Kovacs K, Lloyd RV \& Cusimano M. Ki-67 in pituitary neoplasms: a review - part I. Neurosurgery 200965 429-437. (doi:10.1227/01.NEU.0000349930.66434.82)

13 De Aguiar PH, Aires R, Laws ER, Isolan GR, Logullo A, Patil C \& Katznelson L. Labeling index in pituitary adenomas evaluated by means of MIB-1: is there a prognostic role? A critical review Neurological Research 201032 1060-1071. (doi:10.1179/ 016164110X12670144737855)

14 Chiloiro S, Bianchi A, Doglietto F, de Waure C, Giampietro A, Fusco A, Iacovazzo D, Tartaglione L, Di Nardo F, Signorelli F et al. Radically resected pituitary adenomas: prognostic role of Ki 67 labeling index in a monocentric retrospective series and literature review. Pituitary 201417 267-276. (doi:10.1007/s11102-013-0500-6)

15 Righi A, Agati P, Sisto A, Frank G, Faustini-Fustini M, Agati R, Mazzatenta D, Farnedi A, Menetti F, Marucci G et al. A classification tree approach for pituitary adenomas. Human Pathology 201243 1627-1637. (doi:10.1016/j.humpath.2011.12.003)

16 Hewedi IH, Osman WM \& El Mahdy MM. Differential expression of cyclin D1 in human pituitary tumors: relation to MIB-1 and p27/Kip1 labeling indices. Journal of the Egyptian National Cancer Institute 201123 171-179. (doi:10.1016/j.jnci.2011.11.003)

17 Mete O, Ezzat S \& Asa SL. Biomarkers of aggressive pituitary adenomas. Journal of Molecular Endocrinology 201249 R69-R78. (doi:10.1530/JME-12-0113)

18 Righi A, Morandi L, Leonardi E, Farnedi A, Marucci G, Sisto A, Frank G, Faustini-Fustini M, Zoli M, Mazzatenta D et al. Galectin-3 expression in pituitary adenomas as a marker of aggressive behavior. Human Pathology 201344 2400-2409. (doi:10.1016/j.humpath.2013.05.020)

19 Di Ieva A, Rotondo F, Syro LV, Cusimano MD \& Kovacs K. Aggressive pituitary adenomas - diagnosis and emerging treatments. Nature Reviews. Endocrinology 201410 423-435. (doi:10.1038/nrendo.2014.64)

20 Lee EH, Kim KH, Kwon JH, Kim HD \& Kim YZ. Results of immunohistochemical staining of cell-cycle regulators: the prediction of recurrence of functioning pituitary adenoma. World Neurosurgery 201481 563-575. (doi:10.1016/j.wneu.2013.09.035)

21 Tye BK. MCM proteins in DNA replication. Annual Review of Biochemistry 199968 649-686. (doi:10.1146/annurev. biochem.68.1.649)

22 Bell SP \& Dutta A. DNA replication in eukaryotic cells. Annual Review of Biochemistry 200271 333-374. (doi:10.1146/annurev.biochem.71. 110601.135425)

23 Nishiyama A, Frappier L \& Méchali M. MCM-BP regulates unloading of the MCM2-7 helicase in late S phase. Genes and Development 201125 165-175. (doi:10.1101/gad.614411)

24 Forsburg SL. Eukaryotic MCM proteins: beyond replication initiation. Microbiology and Molecular Biology Reviews 200468 109-131. (doi:10.1128/MMBR.68.1.109-131.2004)

25 Mukherjee P, Winter SL \& Alexandrow MG. Cell cycle arrest by transforming growth factor $\beta 1$ near G1/S is mediated by acute abrogation of prereplication complex activation involving an Rb-MCM interaction. Molecular and Cellular Biology 201030 845-856. (doi:10.1128/MCB.01152-09)

26 Wei Q, Li J, Liu T, Tong X \& Ye X. Phosphorylation of minichromosome maintenance protein 7 (MCM7) by cyclin/cyclin-dependent kinase affects its function in cell cycle regulation. Journal of Biological Chemistry 2013288 19715-19725. (doi:10.1074/jbc.M112.449652) 
27 Moreno SP, Bailey R, Campion N, Herron S \& Gambus A. Polyubiquitylation drives replisome disassembly at the termination of DNA replication. Science 2014346 477-481. (doi:10.1126/science.1253585)

28 Stoeber K, Tisty TD, Happerfield L, Thomas GA, Romanov S, Bobrow L, Williams ED \& Williams GH. DNA replication licensing and human cell proliferation. Journal of Cell Science 2001114 2027-2041.

29 Li SS, Xue WC, Khoo US, Ngan HY, Chan KY, Tam IY, Chiu PM, Ip PP, Tam KF \& Cheung AN. Replicative MCM7 protein as a proliferation marker in endometrial carcinoma: a tissue microarray and clinicopathological analysis. Histopathology 2005463 307-313. (doi:10.1111/j.1365-2559.2005.02069.x)

30 Ren B, Yu G, Tseng GC, Cieply K, Gavel T, Nelson J, Michalopoulos G, Yu YP \& Luo JH. MCM7 amplification and overexpression are associated with prostate cancer progression. Oncogene 200625 1090-1098. (doi:10.1038/sj.onc.1209134)

31 Gambichler T, Shtern M, Rotterdam S, Bechara FG, Stücker M, Altmeyer P \& Kreuter A. Minichromosome maintenance proteins are useful adjuncts to differentiate between benign and malignant melanocytic skin lesions. Journal of the American Academy of Dermatology 200960 808-813. (doi:10.1016/j.jaad.2009.01.028)

32 Nishihara K, Shomori K, Tamura T, Fujioka S, Ogawa T \& Ito H. Immunohistochemical expression of geminin in colorectal cancer implication of prognostic significance. Oncology Reports 200921 1189-1195. (doi:10.3892/or_00000340)

33 Giaginis C, Vgenopoulou S, Vielh P \& Theocharis S. MCM proteins as diagnostic and prognostic tumor markers in the clinical setting. Histology and Histopathology 201025 351-370.

34 Saydam O, Senol O, Schaaij-Visser TB, Pham TV, Piersma SR, StemmerRachamimov AO, Wurdinger T, Peerdeman SM \& Jimenez CR. Comparative protein profiling reveals minichromosome maintenance (MCM) proteins as novel potential tumor markers for meningiomas. Journal of Proteome Research 20109 485-494. (doi:10.1021/pr900834h)

35 Erkan EP, Strobel T, Lewandrowski G, Tannous B, Madlener S, Czech T, Saydam N \& Saydam O. Depletion of minichromosome maintenance protein 7 inhibits glioblastoma multiforme tumor growth in vivo. Oncogene 201433 4778-4785. (doi:10.1038/onc.2013.423)

36 Liu M, Li JS, Tian DP, Huang B, Rosqvist S \& Su M. MCM2 expression levels predict diagnosis and prognosis in gastric cardiac cancer. Histology and Histopathology 2013284 481-492. (doi:10.14670/HH-28.481)

37 Hua C, Zhao G, Li Y \& Bie L. Minichromosome maintenance (MCM) family as potential diagnostic and prognostic tumor markers for human gliomas. BMC Cancer 201414 526. (doi:10.1186/1471-2407-14-526)

38 Ha S-A, Shin SM, Namkoong H, Lee H, Cho GW, Hur SY, Kim TE \& Kim JW. Cancer-associated expression of minichromosome maintenance 3 gene in several human cancers and its involvement in tumorigenesis. Clinical Cancer Research 200410 8386-8395. (doi:10.1158/1078-0432.CCR-04-1029)

39 Facoetti A, Ranza E, Grecchi I, Benericetti E, Ceroni M, Morbini P \& Nano R. Immunohistochemical evaluation of minichromosome maintenance protein 7 in astrocytoma grading. Anticancer Research $2006263513-3516$.
40 Fujioka S, Shomori K, Nishihara K, Yamaga K, Nosaka K, Araki K, Haruki T, Taniguchi Y, Nakamura H \& Ito H. Expression of minichromosome maintenance 7 (MCM7) in small lung adenocarcinomas (pT1): prognostic implication. Lung Cancer 200965 223-229. (doi:10.1016/jlungcan.2008.11.007)

41 Luo J-H. Oncogenic activity of MCM7 transforming cluster. World Journal of Clinical Oncology 20112 120-124. (doi:10.5306/ wjco.v2.i2.120)

42 Toyokawa G, Masuda K, Daigo Y, Cho HS, Yoshimatsu M, Takawa M, Hayami S, Maejima K, Chino M, Field HI et al. Minichromosome maintenance protein 7 is a potential therapeutic target in human cancer and a novel prognostic marker of non-small cell lung cancer. Molecular Cancer 201110 65. (doi:10.1186/1476-4598-10-65)

43 Lobato S, Tafuri A, Fernandes PÁ, Caliari MV, Silva MX, Xavier MA \& Vago AR. Minichromosome maintenance 7 protein is a reliable biological marker for human cervical progressive disease. Journal of Gynecologic Oncology 201223 11-15. (doi:10.3802/jgo.2012.23.1.11)

44 Fristrup N, Birkenkamp-Demtröder K, Reinert T, Sanchez-Carbayo M, Segersten U, Malmström PU, Palou J, Alvarez-Múgica M, Pan CC, Ulhøi BP et al. Multicenter validation of cyclin D1, MCM7, TRIM29, and UBE2C as prognostic protein markers in non-muscle-invasive bladder cancer. American Journal of Pathology 2013182 339-349. (doi:10.1016/j.ajpath.2012.10.017)

45 Ishibashi Y, Kinugasa T, Akagi Y, Ohchi T, Gotanda Y, Tanaka N, Fujino S, Yuge K, Kibe S, Yoshida N et al. Minichromosome maintenance protein 7 is a risk factor for recurrence in patients with Dukes C colorectal cancer. Anticancer Research 201434 4569-4575.

46 Sánchez-Tejada L, Sánchez-Ortiga R, Moreno-Pérez Ó, Fajardo Montañana C, Niveiro M, Tritos NA \& Picó Alfonso AM. Pituitary tumor transforming gene and insulin-like growth factor 1 receptor expression and immunohistochemical measurement of Ki-67 as potential prognostic markers of pituitary tumors aggressiveness. Endocrinología $y$ nutrición : órgano de la Sociedad Espanöla de Endocrinología y Nutrición 201360 358-367. (doi:10.1016/j.endonu.2012.09.005)

47 Xu Y, Wang Y, Ma G, Wang Q \& Wei G. CUL4 is overexpressed in pituitary adenomas and regulates pituitary tumor cell proliferation. Journal of Neuro-Oncology 2014116 625-632. (doi:10.1007/ s11060-013-1349-2)

48 Hadzhiyanev A, Ivanova R, Nachev E, Elenkova A, Yaneva M, Zaharieva S, Marinov M, Surchev J \& Ivanova A. Evaluation of prognostic utility of MIB-1 and p53 expression in pituitary adenomas: correlations with clinical behaviour and follow-up results. Biotechnology, Biotechnological Equipment 201428 502-507. (doi:10.1080/13102818.2014.932510)

49 Trouillas J, Roy P, Sturm N, Dantony E, Cortet-Rudelli C, Viennet G, Bonneville JF, Assaker R, Auger C, Brue T et al. A new prognostic clinicopathological classification of pituitary adenomas: a multicentric case-control study of 410 patients with 8 years post-operative follow-up. Acta Neuropathologica 2013126 123-135. (doi:10.1007/ s00401-013-1084-y)

Received 13 June 2015

Revised version received 24 November 2015

Accepted 30 November 2015 